\title{
7. E-commerce development in rural China
}

Sherry Tao Kong

\section{General introduction of e-commerce in China}

Against the backdrop of its remarkable economic progress, China has seen rapid development in the application of information and communication technology (ICT). With the provision of extensive telecommunication infrastructure, China is digitalising rapidly. As a direct result of the expansion of digital networks, the rate of internet penetration in China has been increasing steadily, currently approaching 60 per cent of the total Chinese population. Given China's population size, this signifies a huge market of consumers, many of whom are ready to embrace the digital world in an enthusiastic and innovative manner. China therefore provides uniquely fertile ground for experiments with and commercialisation of digital business models.

There has been remarkable growth in digitalisation over the past decade. From 2007 to 2016, the rate of internet penetration in China increased from 16 per cent to 53.2 per cent overall, surging from 26 per cent to 69.1 per cent in urban areas and from 7.4 per cent to 33.1 per cent in rural areas (China Internet Network Information Center 2017). Along with greater internet penetration in China, the number of internet users increased at an average pace of nearly 20 per cent per annum for at least a decade after 2006. By 2018, the total number of internet users in China reached 828.5 million and broadband networks had connected 378 million households, of which 87.5 per cent were using optical fibre. Alongside this remarkable digitalisation process, a defining feature of Chinese internet users is their utilisation of mobile devices. By mid-2018, 788 million Chinese were using mobile devices to access the internet, accounting for 98.3 per cent of all internet users.

Along with the rapid expansion and upgrading of internet infrastructure, as well as the formation of the enormous internet user population, the digital economy has become an increasingly important part of China's economic landscape. Based on the 2018 China's Internet Industry Report (iResearch Global 2018), the gross value of the digital economy reached RMB27.2 trillion in 2017, accounting for 32.9 per cent of national gross domestic product (GDP) -2.6 percentage points higher than in 
2016. ${ }^{1}$ Moreover, it is particularly noteworthy that the digital economy contributed approximately 55 per cent of overall GDP growth, serving as a powerful engine of growth and encouraging a range of socioeconomic developments in China.

E-commerce constitutes a considerable part of the digital economy. Admittedly, China was not an early starter in e-commerce development compared with other countries. The very first online transaction in China was completed in April 1998 and growth during the subsequent decade was slow (Cao and Zhang 2009). The take-off in China's e-commerce came in 2008 when it exhibited exponential growth. Over the course of the subsequent decade, the total transaction value of e-commerce achieved a remarkable tenfold growth, from RMB3.14 trillion to RMB31.63 trillion (Xinhua News Agency 2019). Today, China has become a leading force in the global digital economy. The country is home to 42 per cent of global e-commerce and its total annual e-commerce transaction value is greater than that of France, Germany, Japan, the United Kingdom and the United States combined (Wang et al. 2017).

During the same period, the annual transaction value of online retail grew sharply. In 2008, online accounted for only 1.3 per cent of total retail sales in China. This share was considerably lower than that in the United States $(3.72$ per cent) and the United Kingdom (4.5 per cent). However, this modest position quickly became history. The total value of online sales in China reached RMB1.89 trillion in 2013 - a more than tenfold rise from the modest RMB130 billion in 2008. China, for the first time, surpassed the United States and became the largest e-commerce market in the world (China E-commerce Research Centre 2016) — a position that has since been further consolidated. In 2016, China's total value of online sales rose to RMB5.33 trillion, accounting for 14.9 per cent of the country's total retail sales. By 2018, the annual online retail sales value reached a staggering RMB9 trillion. In the meantime, the population of online business owners grew from 7.9 million in 2008 to 50 million in 2016. Regardless of the measure one uses, China is by far the world's largest online retail market.

It is not simply the astounding economic value or the remarkable growth rates that make e-commerce development in China a topic worthy of discussion. More importantly, as a form of business activity, e-commerce provides exciting opportunities for job creation, increasing household incomes and skill formation. In particular, e-commerce, especially online retail sales, has sparked hopes about its potential benefits for more inclusive rural development.

1 During its presidency of the G20 in 2016, China supported global efforts to define the digital economy within the G20 Digital Economy Development and Cooperation Initiative. That initiative defined the digital economy as 'a broad range of activities that include using digitalised information and knowledge as the key factor of production, modern information networks as an important activity space, and the effective use of ICT as an important driver of productivity growth and economic structure optimisation'. 
Traditionally, retail businesses attached a great deal of importance to their physical establishment - a precondition for development. For example, a shopfront is required to display goods for sale and advertise services provided; bank branches or ATMs are required to enable payments and process financial transactions. Such development preconditions generally left rural areas in a less advantageous position compared with cities. However, the same need not apply in the context of e-commerce. In contrast to the traditional offline business model, e-commerce is arguably location-neutral; as long as there is internet access and logistical systems are in place, rural areas are not immediately disadvantaged because of a lower level of general development. Because of this, e-commerce seems to be able to offer a more level playing field for rural areas to catch up with urban levels of development. As a result, there is much hope that the digital economy-in particular, e-commerce-can serve as an effective vehicle to generate growth, alleviate poverty, reduce inequality and improve various dimensions of social development in rural China.

However, while e-commerce in rural China holds much exciting potential, in practice, the actual level of e-commerce remains seriously underdeveloped in rural areas compared with cities. Over the past decade, despite an increase in the number of internet users in rural China-from 23.11 million in 2006 to 201 million in 2016 - the value of online sales in rural China grew only modestly, reaching RMB353 million in 2015 and RMB482 million in 2016. Based on data from the Ministry of Commerce, rural online retailing increased by 39.1 per cent in 2017 . The total value of online sales of agricultural products reached RMB243.7 billionincreasing by 53.3 per cent. By the end of 2017, the number of online stores being run from rural areas was 9.86 million-an increase of 20.7 per cent.

However, it remains to be investigated whether, and to what extent, rural e-commerce can realise its promise of delivering prosperity and reducing inequality. Against the backdrop of the general development of e-commerce in China, this chapter focuses on the important area of development of rural e-commerce, particularly that of 'Taobao villages' (administrative villages where both the aggregate transaction value of e-commerce and the total number of online businesses registered in the village have reached a certain threshold). In addition, by considering the related research findings and national- and subnational-level policies, we provide some initial thoughts on the impacts of rural e-commerce development and the policies required to unleash the potential of the digital economy. 


\section{E-commerce development in rural China and related research}

\section{General assessment of the extant literature}

Rural e-commerce essentially means using the internet to purchase products from and sell goods to rural areas. The possibility of engaging the rural population in both production and consumption brings great development potential. Indeed, as early as 1984 , the International Telecommunication Union proposed eradicating poverty through developing telecommunications infrastructure. A number of academic studies also demonstrated that the application of ICT had significant effects on education, poverty reduction and employment opportunities (Sumanjeet 2009).

In the case of China, it is generally accepted that the development of rural e-commerce is improving both local economies and household livelihoods, especially by providing opportunities for the economic advancement of people living in rural and remote areas (Lin et al. 2016). The belief that poverty alleviation can be achieved through the development of rural e-commerce is widely held, to the extent that the Chinese Government and organisations such as the World Bank have engaged in the active promotion of rural e-commerce. In the meantime, while the value of rural online sales accounts for only a small fraction of the total in China, rural areas are widely seen as a great untapped market. Moreover, in anticipation of the gradual saturation of online markets in urban areas, a large number of e-commerce enterprises have begun expanding their businesses into rural markets. As such, the opportunities for rural e-commerce development have become apparent and have been enthusiastically embraced by both the private sector and the government. Recent studies such as Liu et al. (2018) provide valuable overview and analysis on the development of rural e-commerce.

While from a business perspective the importance of rural e-commerce may be more than obvious, research on the actual impact of rural e-commerce remains limited. Furthermore, existing studies often rely on anecdotal evidence or are based on analyses conducted by enterprises within the industry.

In contrast, formal studies based on reliable microlevel data are rare, with a small number of exceptions, including, notably, Couture et al. (2018) and Fan et al. (2018). This probably has much to do with the fact that online sales data are too often available only from the platform on which the transactions take place. Consequently, although a sizeable body of case studies has been produced by scholars and commentators, academically rigorous research on China's rural e-commerce remains scarce. 
Moreover, when assessing the actual impact of rural e-commerce development, the findings are revealing. As one of the only few academic studies that investigates this topic, Couture et al. (2018) found that rural e-commerce resulted in stronger consumption-side effects as e-commerce terminals offered lower prices, greater convenience and increased product variety. For households, gains in household purchasing power were strongest for durable products. However, rural e-commerce was found to have no significant effects on the local economy and fewer pro-competition effects on local retail prices. Furthermore, production-side effects are less immediate: in the absence of complementary interventions-such as business training, access to credit or targeted online promotions-few productionside effects are likely to materialise for the average rural marketplace in the short to medium runs.

The above results demonstrate that realisation of the promise of e-commerce for rural development is not automatic. Reliable internet access, trustworthy digital transaction methods and convenient parcel delivery and logistics services are necessary but insufficient conditions to realise the promise of e-commerce in less-developed areas. The development of e-commerce in rural areas requires a combination of grassroots organic growth and supportive government policies.

In sum, when entrepreneurship encounters conducive conditions, rural e-commerce flourishes.

\section{An important area of rural e-commerce development: Taobao villages}

Taobao villages are a powerful example of the development of rural e-commerce in China. The official definition of a Taobao village is an administrative village where the total annual value of e-commerce transactions-or gross merchandise volume (GMV) - is no less than RMB10 million (approximately, A $\$ 2$ million) and there are at least 100 active online stores or a minimum of 10 per cent of local households are operating online stores (AliResearch 2016). In short, a Taobao village is a cluster of e-commerce businesses operating in a rural area.

Such villages are called 'Taobao' because the statistics used to calculate the GMV of online retailing are taken from Taobao.com as the primary marketplace. Taobao.com and the associated Tmall.com-both provided by the Alibaba Group Holding Limited-are the largest e-commerce platforms on which to buy and sell products online. In 2014, Taobao and Tmall accounted for 81.5 per cent of the total value of GMV in China. As the e-commerce market expands at a staggering pace, competition between various online platforms has become increasingly heated. Despite strong rivalry from JD.com and others, Alibaba remains by far 
the largest e-commerce platform provider, accounting for 58.2 per cent of market share in 2018-more than three times larger than the next player, JD.com. As a result, the development of Taobao villages illustrates the general patterns of growth of rural e-commerce.

The first Taobao village was officially approved by Alibaba in 2009 and, by 2013, the number of such villages slowly climbed to 20 . What followed then was mindboggling: within a year, the total number of Taobao villages increased to 212 - a tenfold growth. In addition, for the first time, 17 Taobao townships emerged. These are townships formed by the congregation of at least three Taobao villages. As is shown in Table 7.1 , during the period 2014-18, the number of Taobao villages and townships grew dramatically, along with rapid overall expansion of e-commerce in China. In these Taobao villages, the number of active online stores also increased, from 70,000 in 2014 to 660,000 in 2018 .

Table 7.1 Number of Taobao villages and Taobao townships

\begin{tabular}{|l|l|r|r|r|r|r|}
\hline & & 2014 & 2015 & 2016 & 2017 & 2018 \\
\hline \multirow{2}{*}{ Taobao village } & Total number & 212 & 778 & 1,311 & 2,118 & 3,202 \\
\cline { 2 - 7 } & Growth rate (\%) & & 267 & 69 & 62 & 51 \\
\hline \multirow{2}{*}{ Taobao township } & Total number & 17 & 71 & 135 & 242 & 363 \\
\cline { 2 - 7 } & Growth rate (\%) & & 318 & 90 & 79 & 50 \\
\hline
\end{tabular}

Source: Nanjing University Space Planning Research Centre and Ali New Village Research Centre (2018).

While it is easy to be impressed by these figures, it is important to put them into perspective. There were 671,729 administrative villages in China in 2016; only 0.2 per cent of them qualified as Taobao villages. Taobao villages account for only a tiny fraction of villages in China as a whole, and so there remains room for further growth of rural e-commerce. With that in mind, it is now useful to extend our study beyond the impressive rates of growth of Taobao villages and distil a number of distinctive patterns that have emerged, particularly over the past five years.

First, the number of provinces with Taobao villages expanded from seven in 2012 (Zhejiang, Guangdong, Jiangsu, Shandong, Fujian, Hebei and Jiangxi) to 24 by 2017, including remote and economically underdeveloped provinces such as Guizhou, Shaanxi, Ningxia and two ethnic autonomous regions, Xinjiang and Guangxi. To some extent, this shows the vitality and reach of e-commerce. At the same time, the greatest increase in Taobao villages was in areas where they first took root, such as Zhejiang, Guangdong, Jiangsu and Shandong provinces. In stark contrast, the increase in the number of Taobao villages in the other provinces has been slow and, in some places, even negative. For example, there were two Taobao 
villages in Yunnan Province in 2015, but this was reduced to one in 2016 and 2017. This growth pattern seems to suggest that the development of rural e-commerce reinforces early advantages and builds on successful initial conditions.

Second-not dissimilar to other aspects of China's economic development-the distribution of Taobao villages exhibits clear regional disparities. Taobao villages are highly concentrated in the eastern coastal region, whereas only a small number are scattered across other regions. In fact, more than 90 per cent of Taobao villages are located in the east, which is also where the fastest growth is observed compared with the rest of China. In contrast, other regions are lagging far behind, with the central region leading the west and north-east by a small margin. Within the eastern region, the provincial distribution is also uneven. The number of Taobao villages in Zhejiang Province is 1,172 , accounting for just over one-third of the total number of Taobao villages in the whole country.

While it is probably unsurprising that the distribution and growth patterns reveal clear regional disparities, this is a particularly interesting angle from which to assess the relationship between the development of the digital economy and that of the traditional economy. Theoretically, e-commerce should be free of geographical limitations, as it operates on the internet and does not depend on any physical presence like traditional brick-and-mortar businesses. However, Taobao villages are clearly clustered in the coastal region, where the economy is generally more developed compared with the rest of the country. This seems to imply that the development of e-commerce is not decoupled from the real economy or the traditional sectors.

Third, the formation and growth processes of Taobao villages can reveal the impact of important laws governing rural e-commerce development. The first generation of Taobao villages all had fairly humble beginnings. They initially appeared on the periphery of cites where residents with relatively low socioeconomic status concentrated. These Taobao storeowners were resourceful and adventurous enough, but the types of products sold were mainly low-cost manufacturing goods targeted at low-income consumers.

Many case studies show that the identification of popular products by one or two individuals heralds the subsequent proliferation of online businesses within their community. Diffusion of information and knowledge is particularly effective and rapid within these 'acquaintance societies' in rural villages at the city fringes. Inspired by successful examples, more people find ways to take advantage of the available conditions to drive online sales. For example, some will discover that existing industrial production in nearby areas offers low-cost products; some find that, by moving deeper into rural areas, they can access more labour and greater production and warehousing space at lower costs. The logistics industries attracted by the expansion of e-commerce into rural areas effectively address the issue of the 'last mile' of parcel delivery. Combined with the powerful market integration 
enabled by online platforms that allow sellers to access the entire national market, reliable shipping services in turn provide further impetus to the growth of rural e-commerce.

In sum, through the lens of the development of Taobao villages, one can see how the traditional rural economy is undergoing digitalisation. As business clusters, Taobao villages are able to take advantage of existing industries, such as processing and manufacturing, and stimulate upgrading and further development of new sectors, such as logistics and e-commerce services. In this process, job opportunities are created, income levels are improved and the wider local community benefits. However, despite their internet origins, the formation and subsequent growth of Taobao villages do not seem to be entirely independent of traditional sectors and the prevailing socioeconomic conditions. As always, there seems to be a set of preconditions. Nevertheless, rural e-commerce clearly offers innovative and proven business models that allow third-party online business platforms to work productively in a rural setting, creating fresh opportunities for the upgrading of the rural economy and better integration into wider markets.

\section{Government policies}

The extraordinary development of rural e-commerce in China is a product of the great vitality of e-commerce as a business model, the vast and underserved domestic demand, the rapid progress of digital technology-particularly the development of digital finance-and a range of other factors. However, it is arguable that this extraordinary development would not have occurred had the government not played a highly supportive and facilitating role. The rest of this section briefly reviews national and subnational policies.

\section{National policies}

At the national level, policies related to rural e-commerce development can be traced back as far as 2001 when the State Council issued the 'Framework for the Technological Development of Agriculture (2001-2010)', ${ }^{2}$ which stressed the need to develop agricultural information technology. In response, the Ministry of Agriculture issued the tenth Five-Year Plan (2001-05), outlining national policies for agricultural and rural economic development. ${ }^{3}$ Consistent with the State Council's framework, this plan emphasised the acceleration of the building of rural economic information systems, the establishment of comprehensive information

2 The State Council issued the official document in April 2001.

3 The document was issued by the Ministry of Agriculture in July 2001. 
networks for agriculture and the further expansion and completion of information networks for the marketing of agricultural products. In the same year, both the Ministry of Technology and the Ministry of Finance issued plans to promote the development of information networks in rural areas. These policies set the scene for many subsequent policies focused on promoting the development of agricultural information networks. Many other national-level organisations also responded with specific policies to promote agricultural development through informatisation.

In 2006, the 'No. 1 Central Document' that outlined the annual strategic priorities for the country made clear the agenda for the development of rural informatisation. This was immediately followed by the release of the National Strategy of Informatisation (2006-20), in which specific goals were announced for the development of internet coverage and information services and systems to serve the rural population and agriculture. It is fair to say the central government attached great importance to rural informatisation and, in response, various line ministries and institutions crafted a wide range of policies to achieve this goal.

Between 2006 and 2013, the national government set a policy agenda that laid out the necessary foundations for rural e-commerce to take root in China, including building and improving the logistics industry, encouraging traditional businesses to engage in online operations, improving the e-commerce environment and developing related service industries. In 2007, the central policymaking agency, the National Development and Reform Commission and the Information Office of the State Council jointly issued the first national plan for e-commerce development, the 'E-Commerce 11th Five-Year Plan'. This plan identified two focal points for development: promoting the coverage and intensity of e-commerce applications and strengthening the development of e-commerce service industries. In addition, a supportive environment, more technical innovation, effective rules and regulations as well as education and public promotion were identified as four important areas to lend fundamental support to e-commerce development. It is also worth mentioning the Broadband China Strategy and Implementation Plan announced by the State Council in 2013. It charted a clear technical path, schedule and milestones as well as supportive measures, which were combined with an additional series of policies aimed at improving e-commerce credit systems and electronic payment processes as well as transaction security, allowing rural e-commerce development to gather further momentum.

Over the past five years, rural e-commerce has become increasingly important. In 2014, the expansion of e-commerce to the countryside was set as a national policy priority in its own right to promote rural economic development, alleviate rural poverty and reduce rural-urban economic disparity. In early 2015, the Poverty Alleviation Office of the State Council listed 'Poverty Alleviation through E-Commerce' as one of the key projects for targeted poverty reduction. Given that China set eradicating poverty by 2020 as a national goal, it is evident the 
central government has great expectations for rural e-commerce as an effective means of income generation in economically backward areas. The degree of policy significance attached to rural e-commerce was even more pronounced in 2017 when, for the first time, the 'No. 1 Central Document' dedicated an entire section to accelerating the development of rural e-commerce. Subsequently, in the 'Opinion on the Implementation of the Rural Revitalisation Strategy' of 2018, the central government outlined a clear plan for the implementation of rural e-commerce development, which indicated that e-commerce was expected to play a major role in promoting rural socioeconomic development, eradicating rural poverty and revitalising the countryside.

\section{Local policies}

At the subnational level, most of the policies that actively promote the development of rural e-commerce were crafted and implemented over the past five years. This is in line with the greater importance placed on rural e-commerce by the central government. The State Council's 'Opinion on Further Developing E-Commerce and Fostering New Driving Forces of the Economy' provided the defining impetus for subnational-particularly county-level—governments to devise specific policies to promote local e-commerce development.

While policies rolled out by county-level governments vary from one locality to another, a central element is their compatibility with the existing conditions and their clear focus on rural e-commerce development. We use Wuyi county as an example to illustrate the range of policies that can be devised by county governments. Wuyi is a small, typical rural county in central Zhejiang Province that has traditionally relied on agriculture. Due to its mountainous location, transportation infrastructure was underdeveloped and the county was economically backward and poverty-stricken. However, the development of rural e-commerce has turned it into a successful example of how this sort of development can promote growth and help transform the countryside. In 2018, six new Taobao villages and one new Taobao township emerged, and the GMV of Wuyi exceeded RMB11.6 billion-a 30 per cent increase.

Over the years, the Wuyi County Government has issued a wide range of policies that can be summarised into four areas. First, a designated organisation was established with a full-time staff and authority to craft and implement e-commerce policies. Second, the county government invited independent consultants to draft a five-year plan for the development of Wuyi's e-commerce. The expertise of independent professionals provided valuable guidance over the strategies for and direction of e-commerce development. Third, the county government offered a range of supports for e-commerce startups. For example, it allocated RMB15 million as an annual grant to fund e-commerce activities, while an e-commerce service centre and association and e-commerce industrial parks were established to 
lend support to online businesses. Fourth, the county government mobilised the media and organised public events to popularise the idea of e-commerce, promote entrepreneurs and create a favourable environment for related innovation.

In addition, the Wuyi County Government built up a coordinated service mechanism, including township and village-level governments, so e-commerce businesses can receive support at all stages of development. For instance, one county-level logistics centre is in Wuyi and an additional 18 township-level branches and 398 villagelevel service stations have spread to all corners of the county, forming a network to facilitate the operation of e-commerce.

To take advantage of the positive spillover effects and economies of scale, Wuyi has made significant efforts to foster the creation of Taobao villages. The county government first identified promising projects in particular villages and provided facilities, such as incubators, to help them take shape. Successful individuals would then inspire others to emulate them and become involved in rural e-commerce. For example, Louwang was the first Taobao village in Wuyi county. It was started by one individual, selling electronic tools online. With the support of the local e-commerce office, the business expanded and a large number of villagers and returned migrants began to participate in other e-commerce activities, bringing genuine returns to the community. In 2018, the total value of online retailing in Louwang amounted to RMB200 million and the average annual villagers' income reached RMB30,000. Louwang village has since been recognised as one of the top 10 specialised Taobao villages in Zhejiang Province.

\section{Implications}

Since the mid-2000s, China has experienced exceptional growth in rural e-commence and has established a rich digital ecosystem, expanding beyond just a few large companies. The development of rural e-commerce-by accessing highly integrated markets via online platforms - is expected to bring significant economic advantages, not least inclusive growth, poverty alleviation and inequality reduction. Motivated by such desirable potential, the Chinese Government not only allowed space for digital companies to experiment, but also introduced a wide range of policies and projects to improve the country's internet infrastructure to promote the development of e-commerce. Today, China has become a significant investor in and consumer of digital technologies.

One area with important policy implications for other developing countries is the role of rural e-commerce as an effective tool to combat poverty. Since 2014, 756 counties have been recognised by the national government as model counties for their introduction of e-commerce into the countryside. Among these, 60 per cent (499) are rated poverty-stricken counties by national standards. By 2017, 832 nationally 
declared poverty-stricken counties had engaged in e-commerce and the transaction value increased by 52.1 per cent, totalling RMB120.8 billion. However, despite the exciting development of e-commerce in rural China, numerous challenges remain before its potential to address rural poverty is fully realised.

To start with, there are different causes of poverty-for example, unfavourable geography, underdeveloped infrastructure or lack of labour and human capital. A common feature of such areas is weak business infrastructure, which manifests itself in a number of ways, all of which translate into concrete obstacles to the development of e-commerce. For example, many of these areas are endowed with high-quality agricultural products; however, their production is often uncoordinated and output is subject to much uncertainty due to weather and other factors, and is therefore unstable. Due to their remote location, these types of poverty-stricken areas face exceedingly high transportation and warehousing costs and low-quality internet services. Statistics show that the cost of logistics is at least four times higher for villages in western China than for those in the coastal region. Another important factor is human capital. Most talent is attracted to economically developed areas, where they can enjoy higher incomes. Poorer areas therefore routinely experience a shortage of skilled labour to operate online businesses and related services. The relatively low levels of education in these areas also make training less effective. The absence of expertise in branding, marketing and retail limits sales. Consequently, the income effects and positive externalities of e-commerce do not automatically lead to a reduction in poverty.

To better unleash the potential of e-commerce, a number of policy implications can be drawn from the development experiences so far. First, leadership and accountability are important. As the experience of Wuyi county demonstrates, the formation of a designated governmental body like its e-commerce development office-with fulltime staff and appropriate authority and funding support-is key to e-commerce policymaking and development. Second, it seems the first-mover effects are critical in the expansion of e-commerce. The example provided by successful individuals is powerful and can inspire others. Therefore, it is useful to identify a small number of promising projects and focus limited resources on fostering these projects. Third, logistics, warehousing, transport and internet connectivity are particularly important for underdeveloped rural areas. Only by effectively reducing the costs of trade can the benefits of access to the entire domestic market through online trading platforms be realised. Lastly, for the above three areas to work, training, education and funding support are needed. In this regard, governments at all levels will need to be decisive and innovative in crafting policies to address the shortage of talent and funding for rural e-commerce development. 


\section{References}

AliResearch (2016), China Taobao Village Research Report (2016), [Online], Alibaba Group, available from: www.aliresearch.com/Blog/Article/detail/id/21242.html.

Cao, L. and Zhang, Z. (2009), The research report of the twelve years of China's e-commerce: 1997-2009, available from: tech.qq.com/2009921e/ebaogao.doc.

China E-commerce Research Centre (2016), The annual monitoring report of Online retail sales of China, available from: www.100ec.cn/zt/upload_data/wllsbg/wllsbg.pdf.

China Internet Network Information Center (2017), China statistical report on internet development.

Couture, V., Faber, B., Gu, Y. and Liu, L. (2018), E-commerce integration and economic development: Evidence from China, NBER Working Paper No. 24384, Cambridge, MA: National Bureau of Economic Research. doi.org/10.3386/w24384.

Fan, J., Tang, L., Zhu, W. and Zou, B. (2018), The Alibaba Effect: Spatial consumption inequality and the welfare gains from e-commerce. Journal of International Economics 114: 203-20. doi.org/10.1016/j.jinteco.2018.07.002.

iResearch Global (2018), 2018 China's internet industry report (the full edition), available from: www.iresearchchina.com/content/details8_40769.html.

Lin, G., Xie, X. and Lv, Z. (2016), Taobao practices, everyday life and emerging hybrid rurality in contemporary China, Journal of Rural Studies 47: 514-23. doi.org/10.1016/ j.jrurstud.2016.05.012.

Liu, M., Huang, J., Zhang, Q. and Gao, S. (2018), What drives the development of e-commerce in rural China-the empirical evidence from the emergence of Taobao Villages. International Association of Agricultural Economists 2018 Conference, 28 July - 2 August. Vancouver, British Columbia.

Nanjing University Space Planning Research Centre and Ali New Village Research Centre (2018), China Taobao Village Development Report (2014-2018), [Online], available from: dy.163.com/v2/article/detail/E4MPSS3H0511B3FV.html.

Sumanjeet (2009), Social implications of electronic commerce, Journal of the Social Sciences 21(2): 91-7. doi.org/10.1080/09718923.2009.11892757.

Wang, K.W., Woetzel, J., Seong, J., Manyika, J., Chui, M. and Wong, W. (2017), Digital China: Powering the economy to global competitiveness, McKinsey Global Institute, December, available from: www.mckinsey.com/featured-insights/china/digital-chinapowering-the-economy-to-global-competitiveness.

Xinhua News Agency (2019), China's total e-commerce transactions increased 10 times in 10 years, CCTV News, 12 April, available from: jingji.cctv.com/2019/04/12/ARTIW9X jnXSiq2QxKCUPA4MC190412.shtml. 
This text is taken from The Chinese Economic Transformation: Views from Young Economists, edited by Ligang Song, Yixiao Zhou and Luke Hurst, published 2019 by ANU Press, The Australian National University, Canberra, Australia. 